\title{
Frontotemporal brain sagging syndrome
}

An SIH-like presentation mimicking FTD

M.R. Wicklund, MD

B. Mokri, MD

D.A. Drubach, MD

B.F. Boeve, MD

J.E. Parisi, MD

K.A. Josephs, MD, MST, MSc

Address correspondence and reprint requests to Dr. Keith A. Josephs, Department of Neurology, Mayo Clinic, 200 First Street SW, Rochester, MN 55905

josephs.keith@mayo.edu
Editorial, page 1370

Supplemental data at www.neurology.org

\section{ABSTRACT}

Background: Behavioral variant frontotemporal dementia (bvFTD) is a relatively well-defined clinical syndrome. It is associated with frontal and temporal lobe structural/metabolic changes and pathologic findings of a neurodegenerative disease. We have been evaluating patients with clinical and imaging features partially consistent with bvFTD but with evidence also suggestive of brain sagging, which we refer to as frontotemporal brain sagging syndrome (FBSS).

Methods: Retrospective medical chart review to identify all patients seen at our institution between 1996 and 2010, who had a clinical diagnosis of FTD and imaging evidence of brain sag.

Results: Eight patients, 7 male and 1 female, were diagnosed with FBSS. The median age at symptom onset was 53 years. All patients had insidious onset and slow progression of behavioral and cognitive dysfunction accompanied by daytime somnolence and headache. Of the 5 patients with functional imaging, all showed evidence of hypometabolism of the frontotemporal regions. On brain MRI, all patients had evidence of brain sagging with distortion of the brainstem; 3 patients had diffuse pachymeningeal enhancement. CSF opening pressure was varied and CSF protein was mildly elevated. A definite site of CSF leak was not identified by myelogram or cisternography, except in one patient with a site highly suggestive of leak who subsequently underwent surgery confirming a CSF leak. In 2 patients with a neuropathologic examination, there was no evidence of a neurodegenerative disease.

Conclusions: This case series demonstrates that FBSS may mimic typical bvFTD but should be recognized as an unusual presentation that is potentially treatable. Neurology ${ }^{\circledR} 2011 ; 76: 1377-1382$

\section{GLOSSARY}

bvFTD = behavioral variant frontotemporal dementia; FBSS = frontotemporal brain sagging syndrome; FTLD = frontotemporal lobar degeneration.

Behavioral variant frontotemporal dementia (bvFTD) is a neurodegenerative disease defined by insidious and progressive decline in behavior and executive functions. ${ }^{1}$ It is characterized by structural and functional changes affecting the frontal and anterior temporal regions. ${ }^{2}$ Neuropathologically, bvFTD is characterized by neuronal loss and gliosis of frontotemporal neocortex and neuronal inclusions that are immunoreactive to tau, TDP-43, or FUS. ${ }^{2-5}$

We have been evaluating patients with presentations mimicking that of bvFTD, but with brain sag noted on MRI. We termed this peculiar constellation of clinical and imaging findings frontotemporal brain sagging syndrome (FBSS).

The aim of this study was to describe clinical and imaging characteristics of 8 patients with FBSS, including 2 with pathologic examination.

METHODS Patient selection. We retrospectively identified all patients seen at the Mayo Clinic between January 1, 1996, and July 1, 2010, for a diagnosis of bvFTD and brain sag by searching medical records for FTD crossed with any of the following terms: brain sag, low CSF pressure, CSF leak, spontaneous intracranial hypotension, or Chiari. Patients who did not satisfy international criteria for $\mathrm{FTD}^{1}$ or in whom imaging was not available were excluded. The clinical records of each patient were reviewed to extract

From the Departments of Neurology (M.R.W., B.M., D.A.D., B.F.B., K.A.J.) and Laboratory Medicine and Pathology (J.E.P.), Mayo Clinic, Rochester, MN.

Disclosure: Author disclosures are provided at the end of the article. 


\begin{tabular}{|c|c|c|c|c|c|c|c|c|c|c|c|}
\hline \multirow{2}{*}{$\begin{array}{l}\text { Table } 1 \\
\text { Patient }\end{array}$} & \multicolumn{11}{|c|}{ Clinical characteristics of 8 patients with FBSS } \\
\hline & Gender & $\begin{array}{l}\text { Age at } \\
\text { onset, } y\end{array}$ & $\begin{array}{l}\text { Orthostatic } \\
\text { headache }\end{array}$ & $\begin{array}{l}\text { Disinhibition/ } \\
\text { apathy }\end{array}$ & Stereotypy & Dysarthria & Dysphagia & $\begin{array}{l}\text { Gait } \\
\text { disturbance }\end{array}$ & $\begin{array}{l}\text { Ocular } \\
\text { abnormality }\end{array}$ & $\begin{array}{l}\text { Movement } \\
\text { disorder }\end{array}$ & $\begin{array}{l}\text { Kokmen } \\
\text { STMS }^{39}\end{array}$ \\
\hline 1 & Male & 53 & - & Both & Vocal tics & Yes & Yes & Yes & - & $\begin{array}{l}\text { Oral buccal } \\
\text { dyskinesia }\end{array}$ & $31 / 38$ \\
\hline 2 & Male & 53 & Occasional & Both & Vocal tics & - & - & Yes & Strabismus & $\begin{array}{l}\text { Dystonic head } \\
\text { posture }\end{array}$ & $29 / 38$ \\
\hline 3 & Male & 49 & Occasional & $\begin{array}{l}\text { Apathy }> \\
\text { disinhibition }\end{array}$ & - & - & - & - & - & $\begin{array}{l}\text { Limb action } \\
\text { tremor }\end{array}$ & 27/30 (MMSE) \\
\hline 4 & Male & 47 & - & Both & Vocal tics & - & - & - & - & - & $35 / 38$ \\
\hline 5 & Male & 54 & - & $\begin{array}{l}\text { Disinhibition > } \\
\text { apathy }\end{array}$ & Vocal tics & - & Yes & Yes & - & - & $34 / 38$ \\
\hline 6 & Male & 50 & Yes & $\begin{array}{l}\text { Apathy }> \\
\text { disinhibition }\end{array}$ & - & Yes & - & Yes & - & - & $20 / 24$ \\
\hline 7 & Male & 45 & Occasional & Both & - & - & - & Yes & Strabismus ${ }^{a}$ & - & $34 / 38$ \\
\hline 8 & Female & 59 & - & $\begin{array}{l}\text { Apathy }> \\
\text { disinhibition }\end{array}$ & - & Yes & Yes & Yes & $\begin{array}{l}\text { Dilated, tonic } \\
\text { right pupil }\end{array}$ & $\begin{array}{l}\text { Upper limb } \\
\text { chorea }\end{array}$ & $18 / 38$ \\
\hline
\end{tabular}

Abbreviations: FBSS $=$ frontotemporal brain sagging syndrome; MMSE = Mini-Mental State Examination; STMS = Short Test of Mental Status ${ }^{a}$ Congenital.

sex, age at onset, presenting symptoms, mental status, laboratory and radiographic findings, and treatments and outcomes.

Standard protocol approvals, registrations, and patient consents. All patients consented to the use of their clinical records for the purpose of research. This study was approved by the Mayo institutional review board.

RESULTS Patient characteristics. We identified 8 patients (7 male) with FBSS. They presented to our institution at a median time of 11 months after symptom onset (range 6-48 months). The presenting clinical characteristics are summarized in table 1.

All 8 patients were noted to have behavioral changes characterized by disinhibition and apathy. Onset was insidious and progressive at a median age of 53 years (range 45-59 years). Each patient had cognitive impairment, though behavioral disturbance was always more prominent. No patient was able to hold employment. Four (patients 1, 2, 4, and 7) were noted to be sexually inappropriate; patient 7 had legal charges for aggressive behavior.

Notably, all patients also had daytime somnolence that began concurrently with the behavior changes. Each patient had headache, with onset occurring either before or concurrently with the behavioral changes. Four patients reported an orthostatic component to their headache, but this was a significant feature in only one (patient 8).

In addition, some patients also had various symptoms suggestive of dysfunction of the deep midline structures, cerebellum, or brainstem, including dysarthria, dysphagia, unsteady gait, ocular abnormalities, and movement disorders; none had falls.

Laboratory findings. Serum. Serum laboratory evaluations were unremarkable except as described. Patient 2 was noted to have an elevated thyroid peroxidase anti- body level of $44.6 \mathrm{IU} / \mathrm{mL}$ (normal $<9.0 \mathrm{IU} / \mathrm{mL}$ ). Patients 6 and 8 were noted to have elevated acetylcholine ganglionic neuronal antibodies values of 1.87 and 0.16 $\mathrm{nmol} / \mathrm{L}$, respectively (normal $\leq 0.02 \mathrm{nmol} / \mathrm{L}$ ).

Of the 3 (patients 2, 4, and 5) who had genetic testing, no mutations in the microtubule-associated protein tau (MAPT) or progranulin $(G R N)$ genes were detected.

CSF. The results of CSF examination are summarized in table e- 1 on the Neurology ${ }^{\circledR}$ Web site at www.neurology.org. The opening pressure varied widely, though only patient 8 had low pressure. The protein was mildly elevated, with normal glucose and cell counts.

Radiologic examination. Brain MRI. In each patient, a characteristic sagging appearance with brainstem swelling was noted (figure 1). The cerebellar tonsils were low-lying, but this was less marked compared to the sagging appearance. In addition, 4/8 (patients 3, 4, 6, and 8) were noted to have transtentorial herniation of the medial temporal lobe structures and corpus callosum. Pachymeningeal enhancement, subdural fluid collections, and atrophy were uncommon (table 2). With the exception of resolving dural enhancement in 2 patients, imaging features remained unchanged over a median follow-up of 13 months (range 5-49 months).

Functional imaging. Of the 5 (patients 1, 2, 4, 5, and 7) who had PET or SPECT, relative hypometabolism of the frontal or temporal lobes was noted (table 2, figure 2).

CT myelogram/cisternography. All except patient 5 had a myelogram or cisternogram. A site of CSF leak was found in only one (patient 8), though nerve root sleeve diverticula or early bladder activity was commonly noted (table 2).

Treatments and outcomes. Over a median follow-up of 11 months (range 4 months- 4 years), all patients 

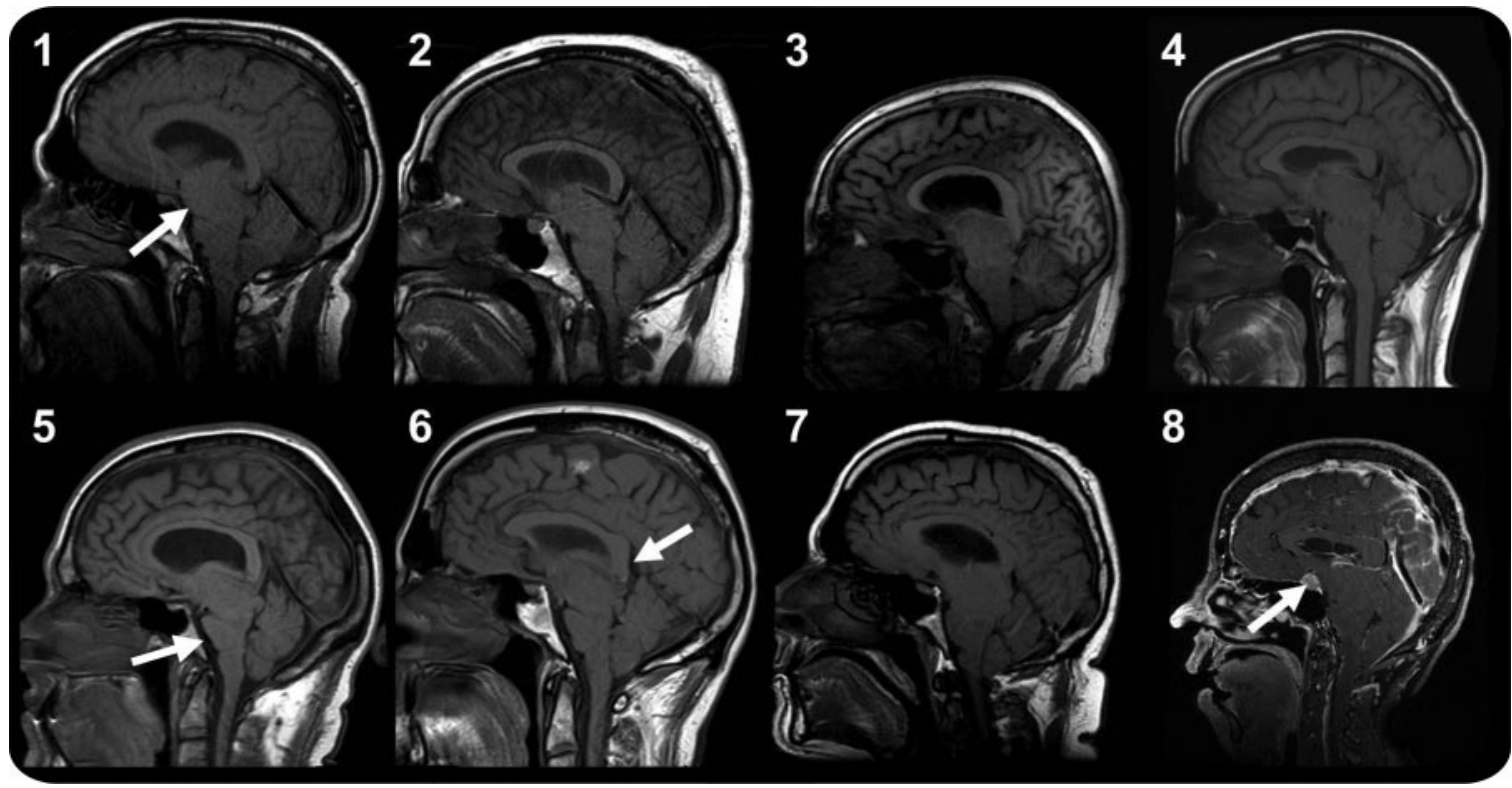

Midline sagittal, T1-weighted brain MRI of 8 patients with FBSS demonstrating the characteristic sagging brain with downward displacement of the cerebellar tonsils, swelling of the midbrain, and flattening of the ventral pons with effacement of the basal cisterns. Gadolinium-enhanced images of patient 8 also demonstrate intense pachymeningeal enhancement and subdural fluid collections with the arrow showing an engorged pituitary gland with mild enlargement. The arrow in patient 1 shows the swollen midbrain and compressed interpeduncular cistern common to each patient while the arrow in patient 5 shows the flattening of the ventral pons. The arrow in patient 6 shows downward displacement of the splenium of the corpus callosum, which is also seen in patients $3,4,5$, and 8 .

demonstrated slow, mild progression of their behavioral and cognitive symptoms, as reported by caregivers. Four patients underwent medical or surgical therapy directed at treatment of CSF leaks.

Patient 2 was given a short course of IV methylprednisolone, without benefit. He died 4 months later of a myocardial infarction.
Over 5 years, patient 6 had 2 courses of IV methylprednisolone and 5 thoracic or lumbar epidural blood patches. With each treatment, he improved in spontaneity for 1 week to 1 month. After one treatment, he maintained improvement for 3 years before his symptoms returned after an acute headache with exercise.

\begin{tabular}{|c|c|c|c|c|c|c|c|c|}
\hline Table 2 & Im & ing findings in 8 & atients with & BSS & & & & \\
\hline 1 & Yes & $Y_{e s}^{a}$ & No & No & $\begin{array}{l}\text { Frontal, anterior temporal } \\
\text { lobes }\end{array}$ & $\begin{array}{l}\text { Cervical root } \\
\text { diverticulum }\end{array}$ & - & 5 \\
\hline 2 & Yes & No & No & No & $\begin{array}{l}\text { Diffuse, }>\text { frontal lobe, } \\
\text { caudate, thalami }\end{array}$ & $\begin{array}{l}\text { Thoracic } \\
\text { root } \\
\text { diverticula }\end{array}$ & Normal & 22 \\
\hline 3 & Yes & No & No & Mild, generalized & - & $\begin{array}{l}\text { Thoracic } \\
\text { root } \\
\text { diverticula }\end{array}$ & - & 5 \\
\hline 4 & Yes & No & No & No & $\begin{array}{l}\text { Diffuse, > frontal, temporal } \\
\text { lobes }\end{array}$ & - & $\begin{array}{l}\text { Increased bladder } \\
\text { activity }\end{array}$ & 16 \\
\hline 5 & Yes & No & No & No & $\begin{array}{l}\text { Left frontotemporal lobes, } \\
\text { right cerebellum }\end{array}$ & - & - & 15 \\
\hline 7 & Yes & No & No & No & $\begin{array}{l}\text { Normal PET/reduced } \\
\text { frontotemporal SPECT }\end{array}$ & Normal & - & 35 \\
\hline 8 & Yes & Yes & Yes & No & - & $\begin{array}{l}\text { Lumbosacral } \\
\text { diverticula }\end{array}$ & - & 11 \\
\hline
\end{tabular}




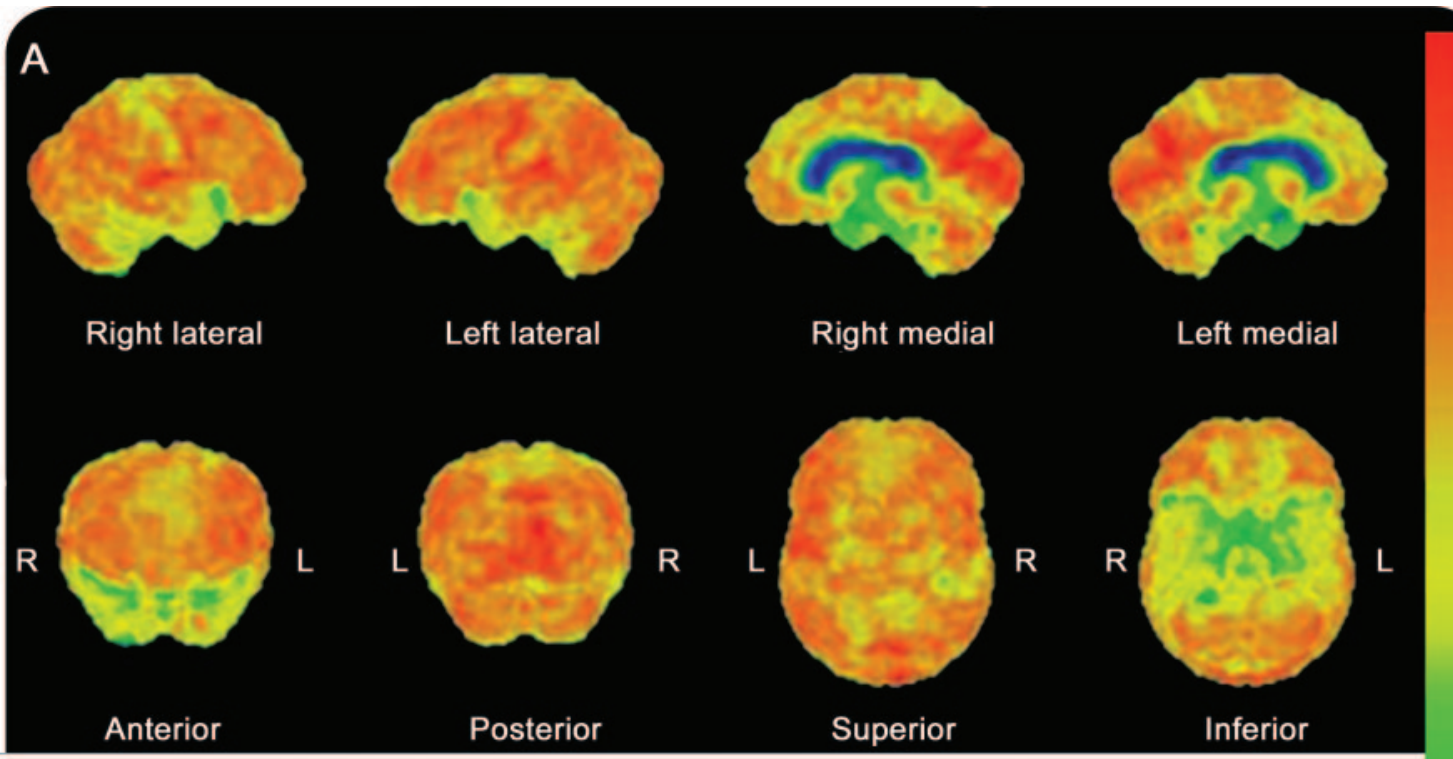

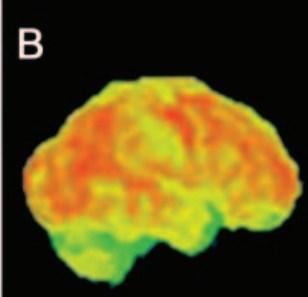

Right lateral

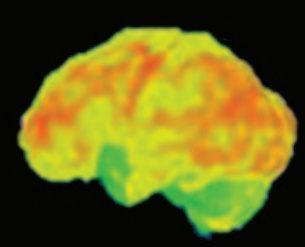

Left lateral

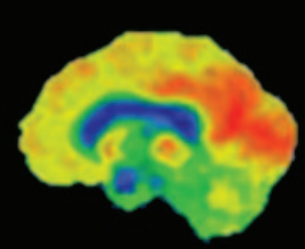

Right medial

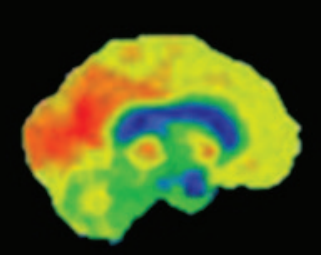

Left medial

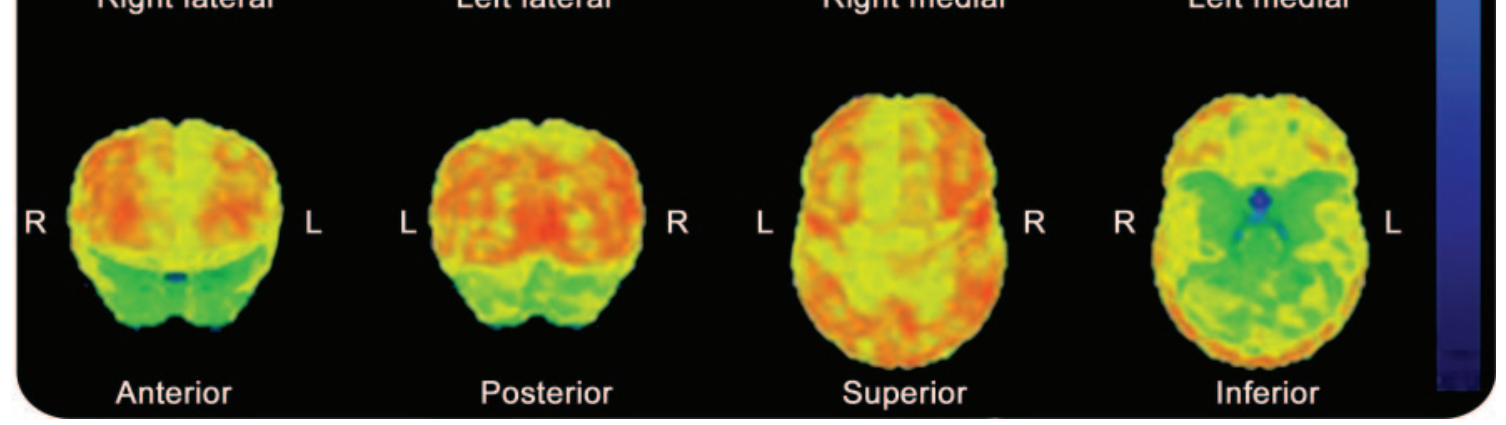

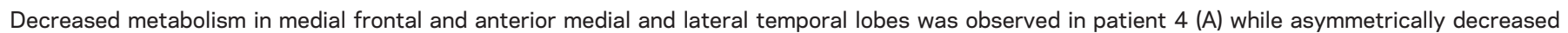
metabolism of the left > right frontal and anterior medial and lateral temporal lobes and bilateral cerebellum was observed in patient 5 (B).

Patient 7 had 2 lumbar epidural blood patches with transient improvement lasting a few days. Oral prednisone for 6 months was not beneficial.

Patient 8 had repair of a lumbar CSF leak. Following surgery, the choreiform movements, cognitive function, and spontaneity improved. However, 2 months later, she declined to her previous level of functioning. Repeat imaging was unchanged and a lumbar epidural blood patch was not beneficial.

Neuropathologic findings. Two patients had detailed neuropathologic examinations. At autopsy, patient 2's brain showed mild generalized atrophy with moderate diffuse senile plaques of the neocortex and sparse neurofibrillary tangles of the medial temporal lobe structures. Patient 6 had a right frontal lobe bi- opsy with nonspecific gliosis and microglial activation noted. There were no intraneuronal inclusions immunoreactive to ubiquitin, tau, or TDP-43 in either case.

DISCUSSION We describe 8 patients with clinical and functional imaging features mimicking bvFTD. ${ }^{1,2,6,7}$ However, these patients also displayed clinical features somewhat atypical for bvFTD, as well as MRI features of brain sag.

The age at onset and male predominance in our patients with FBSS is typical of bvFTD. ${ }^{8}$ However, our patients with FBSS also had daytime somnolence and headache, and some had dysarthria, dysphagia, gait disturbance, ocular abnormalities, or movement disorders. 
These are not typical features of bvFTD, although some do occur in FTD with motor neuron disease, familial FTD, and extrapyramidal syndromes. ${ }^{4}$

Furthermore, patients with FBSS do not show frontotemporal atrophy commonly seen in bvFTD, although they do show frontotemporal hypometabolism. ${ }^{2}$ Lack of atrophy is rare, although it has been described, in pathologically confirmed frontotemporal lobar degeneration (FTLD). ${ }^{9}$ However, neuropathologic examination, when available, did not demonstrate histopathologic changes consistent with FTLD. 2,4,5,8

The lack of typical MRI or pathologic findings suggests a different etiology of the clinical bvFTDlike phenotype in FBSS. The sagging brain likely leads to mechanical forces on frontotemporal structures or their circuits. Decreased salient network connectivity within the cortices, deep midline, and brainstem structures with enhanced cortical default mode network connectivity has been associated with bvFTD. ${ }^{10}$ The marked distortion of the deep midline and brainstem structures in FBSS may disrupt these networks in a similar pattern. In addition, disruption of the cerebellar networks modulating inputs to the frontotemporal circuits may also be playing a role. ${ }^{11}$

The sagging brain in FBSS may be due to a CSF leak or spontaneous intracranial hypotension, where brain sag is also a common imaging finding. ${ }^{12-16} \mathrm{In}$ fact, CSF leaks have been previously implicated in the presentations of $\mathrm{FTD}^{17-19}$ and in patients with deep brain swelling with few neurologic symptoms and scarce pachymeningeal enhancement. ${ }^{20}$ However, patients with FBSS often lacked the most common clinical and imaging manifestations of CSF leaks: orthostatic headache ${ }^{16,21}$ and pachymeningeal enhancement. ${ }^{13,22,23}$ Furthermore, CSF hypotension and a definite leak was found in only one patient, and no patient had complete response to therapy directed at a leak. Nevertheless, a variety of presentations of CSF leaks are becoming increasingly recognized 17-19,24-33: pachymeningeal enhancement can be absent, opening pressure can be normal in a significant minority, ${ }^{34-36} \mathrm{CT}$ myelography may only show meningeal diverticula as leaks can be difficult to visualize, ${ }^{22}$ early bladder activity on cisternography occurs in high frequency in active leaks, $22,37,38$ and lack of sustained improvement with epidural blood patch is not uncommon. ${ }^{22,37}$ Thus, the brain sagging in FBSS likely is due to an unrecognized CSF leak, but we cannot exclude other, as yet, unidentified etiology.

Our study has several limitations. There is a lack of consistent neuropsychological data and sufficient follow-up to demonstrate clinical and imaging progression. Resolution of the brain sag and frontotem- poral hypometabolism after treatment for a CSF leak would be helpful to demonstrate pathogenicity of the leaks.

We have identified a group of patients presenting with insidious and progressive behavior and cognitive changes mimicking bvFTD. However, the marked brain sagging likely reflects an etiology different from that causing typical bvFTD. We have termed this FBSS. It is important to recognize FBSS since this is a potentially reversible syndrome.

\section{DISCLOSURE}

Dr. Wicklund, Dr. Mokri, and Dr. Drubach report no disclosures. Dr. Boeve receives royalties from the publication of Behavioral Neurology of Dementia (Cambridge University Press, 2009); has received honoraria from the American Academy of Neurology; and receives research support from Cephalon, Inc., Allon Therapeutics, Inc., the NIH/NIA, and the Alzheimer's Association. Dr. Parisi serves as a Section Editor for Neurology ${ }^{\circledR}$; serves on the US Government Defense Health Board and as Chair of the Subcommittee for Laboratory Services and Pathology; receives royalties from publishing Principles \& Practice of Neuropathology, 2nd ed. (Oxford University Press, 2003); and receives research support from the NIH. Dr. Josephs receives research support from the NIH and the Dana Foundation.

Received September 1, 2010. Accepted in final form December 20, 2010.

\section{REFERENCES}

1. Neary D, Snowden JS, Gustafson L, et al. Frontotemporal lobar degeneration: a consensus on clinical diagnostic criteria. Neurology 1998;51:1546-1554.

2. McKhann G, Albert M, Grossman M, et al. Clinical and pathological diagnosis of frontotemporal dementia: report of the work group on frontotemporal dementia and Pick's disease. Arch Neurol 2001;58:1803-1809.

3. Munoz D, Dickson D, Bergeron C, et al. The neuropathology and biochemistry of frontotemporal dementia. Ann Neurol 2003;54:S24-S28.

4. Josephs K. Frontotemporal dementia and related disorders: deciphering the enigma. Ann Neurol 2008;64:4-14.

5. Mackenzie I, Neumann M, Bigio E, et al. Nomenclature and nosology for neuropathologic subtypes of frontotemporal lobar degeneration: an update. Acta Neuropathol 2010;119:1-4.

6. Miller B, Diehl J, Freedman M, et al. International approaches to frontotemporal dementia diagnosis: from social cognition to neuropsychology. Ann Neurol 2003;54: S7-S10.

7. Hodges J. Frontotemporal dementia (Pick's disease): clinical features and assessment. Neurology 2001;56:S6-S10.

8. Johnson J, Diehl J, Mendez M, et al. Frontotemporal lobar degeneration: demographic characteristics of 353 patients. Arch Neurol 2005;62:925-930.

9. Josephs KA, Whitwell JL, Jack CR, Parisi JE, Dickson DW. Frontotemporal lobar degeneration without lobar atrophy. Arch Neurol 2006;63:1632-1638.

10. Zhou J, Greicius M, Gennatas E, et al. Divergent network connectivity changes in behavioural variant frontotemporal dementia and Alzheimer's disease. Brain 2010;133: 1352-1367.

11. Schmahmann JD, Sherman JC. The cerebellar cognitive affective syndrome. Brain 1998;121:561-579. 
12. Fishman R, Dillon W. Dural enhancement and cerebral displacement secondary to intracranial hypotension. Neurology 1993;43:609-611.

13. Pannullo S, Reich J, Krol G, Deck M, Posner J. MRI changes in intracranial hypotension. Neurology 1993;43: 919-926.

14. Schievink W, Meyer F, Atkinson J, Mokri B. Spontaneous spinal cerebrospinal fluid leaks and intracranial hypotension. J Neurosurg 1996;84:598-605.

15. Chung S, Kim J, Lee M. Syndrome of cerebral spinal fluid hypovolemia: clinical and imaging features and outcome. Neurology 2000;55:1321-1327.

16. Mokri B, Piepgras D, Miller G. Syndrome of orthostatic headaches and diffuse pachymeningeal gadolinium enhancement. Mayo Clin Proc 1997;72:400-413.

17. Hong M, Shah GV, Adams KM, Turner RS, Foster NL. Spontaneous intracranial hypotension causing reversible frontotemporal dementia. Neurology 2002;58:12851287.

18. Sayao AL, Heran MK, Chapman K, Redekop G, Foti D. Intracranial hypotension causing reversible frontotemporal dementia and coma. Can J Neurol Sci 2009;36:252-256.

19. Walker L, DeMeulemeester C. Spontaneous intracranial hypotension masquerading as frontotemporal dementia. Clin Neuropsychol 2008;22:1035-1053.

20. Savoiardo M, Minati L, Farina L, et al. Spontaneous intracranial hypotension with deep brain swelling. Brain 2007; 130:1884-1893.

21. Mea E, Chiapparini L, Savoiardo M, et al. Clinical features and outcomes in spontaneous intracranial hypotension: a survey of 90 consecutive patients. Neurol Sci 2009; 30(suppl 1):S11-S13.

22. Schievink WI. Spontaneous spinal cerebrospinal fluid leaks: a review. Neurosurg Focus 2000;9:e8.

23. Forghani R, Farb RI. Diagnosis and temporal evolution of signs of intracranial hypotension on MRI of the brain. Neuroradiology 2008;50:1025-1034.

24. Beck CE, Rizk NW, Kiger LT, et al. Intracranial hypotension presenting with severe encephalopathy: case report. J Neurosurg 1998;89:470-473.

25. Dhillon AK, Rabinstein AA, Wijdicks EF. Coma from worsening spontaneous intracranial hypotension after subdural hematoma evacuation. Neurocrit Care 2010;12: 390-394.

26. Evans RW, Mokri B. Spontaneous intracranial hypotension resulting in coma. Headache 2002;42:159-160.
27. Fedi M, Cantello R, Shuey NH, et al. Spontaneous intracranial hypotension presenting as a reversible dorsal midbrain syndrome. J Neuroophthalmol 2008;28:289-292.

28. Ferrante E, Arpino I, Citterio A, Savino A. Coma resulting from spontaneous intracranial hypotension treated with the epidural blood patch in the Trendelenburg position pre-medicated with acetazolamide. Clin Neurol Neurosurg 2009;111:699-702.

29. Khan JA, McAtamney D, Farling PA. Epidural blood patch for hypoactive-hypoalert behaviour secondary to spontaneous intracranial hypotension. Br J Anaesth 2010; 104:508-509.

30. Pakiam AS, Lee C, Lang AE. Intracranial hypotension with parkinsonism, ataxia, and bulbar weakness. Arch Neurol 1999;56:869-872.

31. Turgut N, Unlu E, Hamamcioglu MK, Guldiken B, Albayram S. Postural tremor as a manifestation of spontaneous intracranial hypotension. J Clin Neurosci 2010;17: 255-257.

32. Vetrugno R, Mascalchi M, Chierichetti F, et al. Hypoactivehypoalert behavior ("psychic akinesia") in intracranial hypotension syndrome. Neurology 2008;71:1452-1454.

33. Whiteley W, Al-Shahi R, Myles L, Lueck CJ. Spontaneous intracranial hypotension causing confusion and coma: a headache for the neurologist and the neurosurgeon. $\mathrm{Br} \mathrm{J}$ Neurosurg 2003;17:456-458.

34. Chung S, Im J-H, Lee J-H, Lee M. Determining factors related to pachymeningeal enhancement on brain MRI in CSF hypovolaemia. Cephalalgia 2004;24:903-905.

35. Fuh JL, Wang SJ, Lai TH, Hseu SS. The timing of MRI determines the presence or absence of diffuse pachymeningeal enhancement in patients with spontaneous intracranial hypotension. Cephalalgia 2008;28:318-322.

36. Mokri B, Hunter S, Atkinson J, Piepgras D. Orthostatic headaches caused by CSF leak but with normal CSF pressures. Neurology 1998;51:786-790.

37. Mokri B. Cerebrospinal fluid volume depletion and its emerging clinical/imaging syndromes. Neurosurg Focus 2000;9:e6.

38. Molins A, Alvárez J, Sumalla J, Titus F, Codina A. Cisternographic pattern of spontaneous liquoral hypotension. Cephalalgia 1990;10:59-65.

39. Kokmen E, Naessens JM, Offord KP. A short test of mental status: description and preliminary results. Mayo Clin Proc 1987;62:281-288.

\section{Neurology ${ }^{\circledR}$ Launches Subspecialty Alerts by E-mail!}

Customize your online journal experience by signing up for e-mail alerts related to your subspecialty or area of interest. Access this free service by visiting http://www.neurology.org/cgi/alerts/ etoc.xhtml or click on the "E-mail Alerts" link on the home page. An extensive list of subspecialties, methods, and study design choices will be available for you to choose from-allowing you priority alerts to cutting-edge research in your field! 